\title{
APLIKASI FUZZY DALAM OPTIMALISASI TRAFFIC LIGHT PERSIMPANGAN JUANDA
}

\author{
Rahma Ramadhani \\ Teknik Sipil, Fakultas Teknik, Universitas Hasyim Asy’ari, E-mail: madhasmart@ gmail.com
}

Imamatul Ummah

Teknik Elektro, Fakultas Teknik, Universitas Hasyim Asy’ari, e-mail: ummah.134@gmail.com

\author{
Abdiyah Amudi \\ Teknik Sipil, Fakultas Teknik, Universitas Hasyim Asy'ari, E-mail: abdiyah.amudi@ yahoo.com
}

\section{Nanndo Yannuansa}

Teknik Elektro, Fakultas Teknik, Universitas Hasyim Asy’ari, e-mail: N4nnd0yan@gmail.com

\begin{abstract}
Abstrak
Kemacetan merupakan permasalahan yang sering terjadi dalam masalah transportasi. Persimpangan Juanda merupakan salah satu persimpangan yang seringkali mengalami kemacetan. Adapun penyebab kemacetan muncul dari banyak hal antara lain adanya hambatan samping, tidak terdapatnya marka hingga traffic light yang bekerja kurang optimal. Berdasarkan dari hasil survey awal diketahui bahwa lama lampu hijau pada masing-masing pendekat tidak disesuaikan dengan berapa banyak mobil dan motor yang lewat. Pendekat utara di mana paling banyak mobil dan motor yang lewat akan tetapi mendapatkan lama lampu hijau yang lebih sedikit dibandingkan pendekat yang lain. Hal ini menunjukkan pengaturan traffic light yang kurang optimal. Penggunaan metode fuzzy diharapkan dapat menajdikan pengaturan traffic light lebih optimal karena lama lampu hijau yang dihasilkan lebih bersifat fleksibel sesuai dengan banyak mobil dan motor yang melewati suatu pendekat. Hasil dari penelitian diperoleh untuk kendaraan yang melewati pendekat utara sebanyak 26 mobil dan 177 persiklus diperoleh lama lampu hijau secara manual 43 detik dan dengan fuzzy 45 detik. Pendekat barat dengan banyak kendaraan yang melewati sebanyak 25 mobil dan 170 motor persiklus mendapat lama lampu hijau secara manual 51 detik dan dengan fuzzy 42 detik. Serta untuk pendekat timur dengan banyak kendaraan yang melewati sebanyak 24 mobil dan 168 motor per siklus mendapat lama lampu hijau secara manual 53 detik dan dengan fuzzy 42 detik.
\end{abstract}

\section{Kata Kunci: Fuzzy, Persimpangan, Traffic Light}

Abstract

Traffic Jam is a problem that often occurs in transportation problems. Juanda Junction is one of the intersections that often experience traffic jam. The causes of traffic jam arise from many things, including the presence of side barriers, the absence of markers so that the traffic light that works is not optimal. Based on the results of the initial survey, it was found that the duration of the green light in each pendeka was not adjusted for how many cars and motorcycles were passing. North approacher where most cars and motorbikes are passing but get fewer duration of green lights than other approaches. This shows less optimal traffic light settings. The use of fuzzy method is expected to make traffic light settings more optimal because the old green light produced is more flexible in accordance with many cars and motorcycles that pass through an approach. The results of the study were obtained for vehicles passing through the northern approacher as many as 26 cars and 177/cycle obtained manually by the green light for 43 seconds and with fuzzy 45 seconds. Western approacher with many vehicles passing by 25 cars and $170 /$ cycle motorbikes received a 51-second manual green light and fuzzy 42 seconds. As well as for the east approacher with many vehicles passing 24 cars and 168 motorcycles/cycle get the green light manually 53 seconds and with fuzzy 42 seconds.

Key Words: Fuzzy, Junction, Traffic Light 


\section{PENDAHULUAN}

Kemacetan merupakan permasalahan yang sering terjadi dalam masalah transportasi yang harus diselesaikan(Zhang, Shi. 2010). Adapun penyebab kemacetan muncul dari banyak hal antara lain adanya hambatan samping, tidak terdapatnya marka hingga traffic light yang bekerja kurang optimal. Persimpangan Juanda I merupakan salah satu persimpangan yang mengalami masalah-masalah tersebut. Karakteristik dari persimpangan dan perilaku pengguna jalan disinyalir turut andil dalam penyebab lalu lintas di persimpangan terkesan ruwet dan sering mengalami kemacetan yang diindikasikan adanya antrian panjang.

Adapun karakteristik persimpangan adalah pada pendekat utara terdapat gang kecil yang jaraknya dekat sekali dengan rambu lalu lintas serta belokan antara pendekat barat dan pendekat utara. Selain itu terdapat Mc Donalds dan SPBU di dekat pendekat utara. Ketiga hal tersebut memunculkan hambatan samping yang dapat menyebabkan kemacetan. Jalan pada pendekat utara tidak terdapat marka serta median menyebabkan kendaraan saling menyalip tanpa aturan. Keberadaan industri di sekitar pendekat utara menyebabkan banyaknya kendaraan berat lalu lalang sekitar pendekat. Kawasan sekitar pendekat barat merupakan kawasan sekolah, hotel serta kantor dinas yang tentunya pada jam-jam kerja akan tampak peningkatan aktivitas. Pada pendekat selatan merupakan kawasan home industry dan pusat oleh-oleh. Namun pada saat penelitian, ruas jalan ini ditutup karena perbaikan jembatan sehingga tidak masuk dalam bahasan penelitian. Pendekat timur merupakan ruas jalan akses utama menuju Bandara Juanda.

Berdasarkan UU No. 22 tahun 2009 mendefinisikan bahwa traffic light yang ditempatkan dalam suatu persimpangan, lokasi penyebrangan dan sebagainya berfungsi untuk meminimalisir titik konflik dari mobilitas kendaraan dari berbagai arah. Namun antrian panjang kemacetan dapat menjadi suatu indikasi sinyal traffic light yang sudah terpasang belum optimal. Sebagian besar penggunaan lampu lalu lintas di Indonesia masih menggunakan sistem pengaturan tetap berdasarkan statistik dari penelitian maupun pengamatan persimpangan (Kukarni dan Waingakar, 2007). Perhitungan durasi untuk masing-masing lampu sinyal berpedoman pada Manual Kapasitas Jalan Indonesia 1997 (MKJI 1997).

Kelemahan dari sistem waktu tetap pada sinyal lalu lintas berkaitan dengan keadaan jalan yang berubahubah setiap saat(Prasetyo, 2016). Lampu hijau yang terlalu pendek untuk antrian yang panjang serta lampu hijau yang panjang untuk antrian yang pendek merupakan salah satu ketidakefektifan yang terjadi dari sistem pengaturan waktu tetap.

Penggunaan fuzzy dengan sistem inferensi mamdani diharapkan mampu menghasilkan lama lampu hijau yang sesuai dengan kondisi jalan. Kelebihan-kelebihan dalam fuzzy anatara lain fleksibel, dapat bekerja dengan teknik kendali konvensional (kusumadewi, dkk, 2010). Dengan kelebihan tersebut diharapkan dapat membantu meminimalisir kemacetan.

\section{METODE}

Metode yang digunakan dalam penelitan ini adalah dengan menggunakan fuzzy dengan sistem inferensi mamdani menggunakan bantuan software Matlab.

\section{A. Tahapan Penelitian}

Adapun tahapan yang dilakukan adalah sebagai berikut:

1. Studi literatur dengan mempelajari beberapa jurnal terkait.

2. Survei lokasi untuk mendapatkan karakteristik jalan dan traffic counting

3. Pengambilan data dilakukan dua hari masingmasing mewakili weekday dan weekend dengan tiga sesi pagi,siang dan sore

4. Pengolahan data menggunakan Matlab

5. Penyajian data berupa hasil perbandingan lama lampu hijau semula dengan lama lampu hijau sesudah menggunakan Matlab.

\section{B. Lokasi Penelitian}

Penelitian dilakukan di persimpangan Juanda 1 yang merupakan lokasi di mana sering terjadi antrian yang cukup panjang.

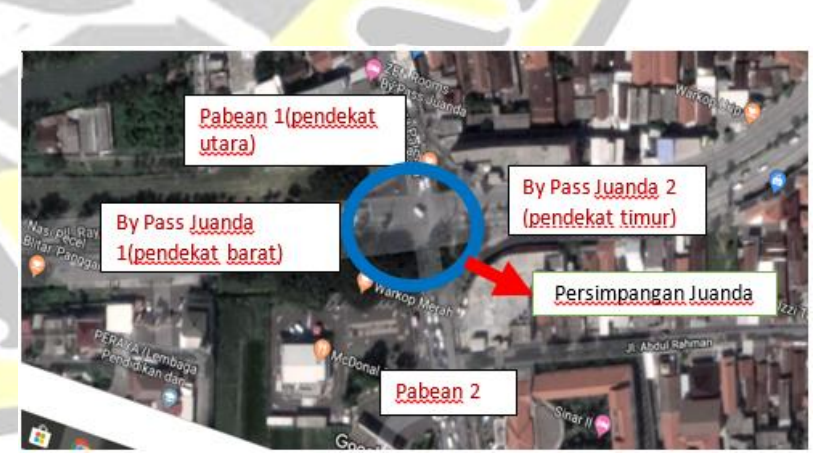

Gambar 1. Persimpangan Juanda I

\section{Peubah yang diamati}

Peubah yang diamati dalam penelitian adalah volume kendaraan dan lama masing-masing lampu pada traffic light. 


\section{Aplikasi Fuzzy dalam Optimalisasi Traffic Light Persimpangan Juanda}

D. Teknik Pengumpulan Data dan Analisis Data

1. Data dikumpulkan melalui survey langsung ke tempat penelitian untuk mendapatkan volume mobil dan motor untuk menjadi input fuzzy.

2. Output dari fuzzy adalah lama lampu hijau pada masing-masing pendekat (pendekat utara, pendekat barat dan pendekat timur)

3. Menentukan derajat keanggotaan masingmasing dari volume mobil dan motor serta lama lampu hijau

4. Melakukan inferensi fuzzy

5. Penentuan lama waktu hijau

\section{HASIL DAN PEMBAHASAN}

Survei awal dilakukan untuk mengetahui lama lampu pada masing-masing pendekat. Data yang diperoleh dari hasil pengamatan peneliti adalah sebagai berikut.

Tabel 1 Data Lampu Traffic Light

\begin{tabular}{llllll}
\hline No & Pendekat & $\begin{array}{c}\text { Lampu } \\
\text { Merah } \\
\text { (detik) }\end{array}$ & $\begin{array}{c}\text { Lampu } \\
\text { Hijau } \\
\text { (detik) }\end{array}$ & $\begin{array}{c}\text { Lampu } \\
\text { Kuning } \\
\text { (detik) }\end{array}$ & Total \\
\hline 1 & $\begin{array}{l}\text { Pendekat } \\
\text { Utara }\end{array}$ & 98 & 43 & 3 & 144 \\
\hline 2 & $\begin{array}{l}\text { Pendekat } \\
\text { Barat }\end{array}$ & 87 & 51 & 3 & 141 \\
\hline 3 & $\begin{array}{l}\text { Pendekat } \\
\text { Timur }\end{array}$ & 82 & 53 & 3 & 137 \\
\hline
\end{tabular}

Sumber: Hasil Pengamatan

Survei selanjutnya adalah untuk menghitung volume kendaraan. Perhitungan volume dilakukan selama dua hari masing-masing mewakili weekday dan weekend. Untuk data volume yang dipakai dalam penelitian ini adalah data volume puncak pada tiap pendekat sehingga dapat diperoleh data sebagai berikut.

Tabel 2 Data Volume Puncak

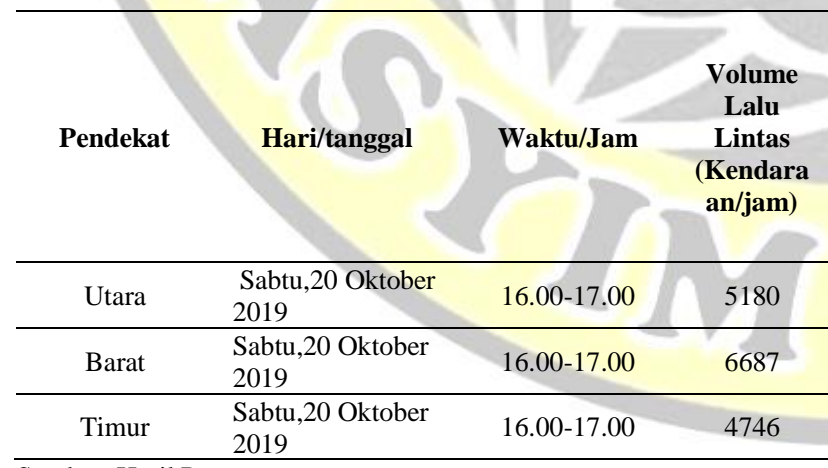

Sumber: Hasil Pengamatan

Adapun data mobil dan motor untuk masingmasing pendekat pada tiap jam dapat dilihat pada tabel berikut.
Tabel 3 Data Masing-masing Mobil dan Motor pada Tiap Pendekat (kendaraan/jam)

\begin{tabular}{ccc} 
Pendekat & $\begin{array}{c}\text { Mobil } \\
\text { (kendaraan/jam) }\end{array}$ & Motor(kendaraan/jam) \\
\hline Utara & 642 & 4522 \\
\hline Barat & 1999 & 4676 \\
\hline Timur & 1204 & 3530 \\
\hline
\end{tabular}

Sumber: Hasil Pengamatan

Kemudian satuan kendaraan/jam diubah menjadi perhitungan jumlah kendaraan per siklus. Sehingga jumlah kendaraan tiap satu jam dikonversikan menjadi jumlah kendaraan per siklus karena output merupakan lama lampu hijau persiklus yang disesuaikan dengan keadaan volume mobil dan motor sehingga jumlah volume kendaraan per siklus adalah sebagai berikut.

Tabel 4 Data Masing-masing Mobil dan Motor pada Tiap Pendekat(kendaraan/siklus)

\begin{tabular}{ccc}
\hline Pendekat & $\begin{array}{c}\text { Mobil } \\
\text { (kendaraan/siklus) }\end{array}$ & $\begin{array}{c}\text { Motor(kendaraan/sikl } \\
\text { us) }\end{array}$ \\
\hline Utara & 26 & 181 \\
\hline Barat & 77 & 180 \\
\hline Timur & 46 & 136 \\
\hline Sumber: Hasil Perhitungan &
\end{tabular}

Berdasarkan data di atas maka ditentukan range untuk mobil $\left[\begin{array}{ll}0 & 150\end{array}\right]$ berdasarkan total mobil di persimpangan dalam satu siklus. Input dalam Matlab ditunjukkan sebagai berikut.

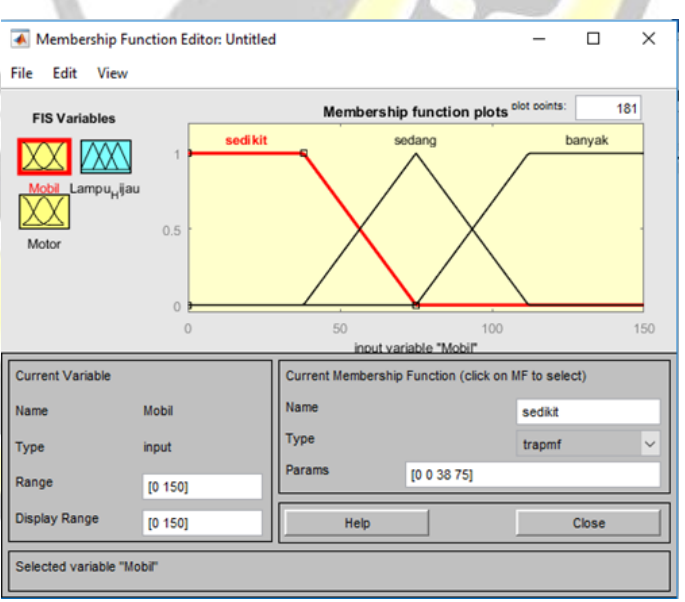

Gambar 2 Input Mobil dalam Matlab

Range motor [0 500] berdasarkan total motor di persimpangan dalam satu siklus. Input dalam Matlab ditunjukkan pada gambar berikut. 


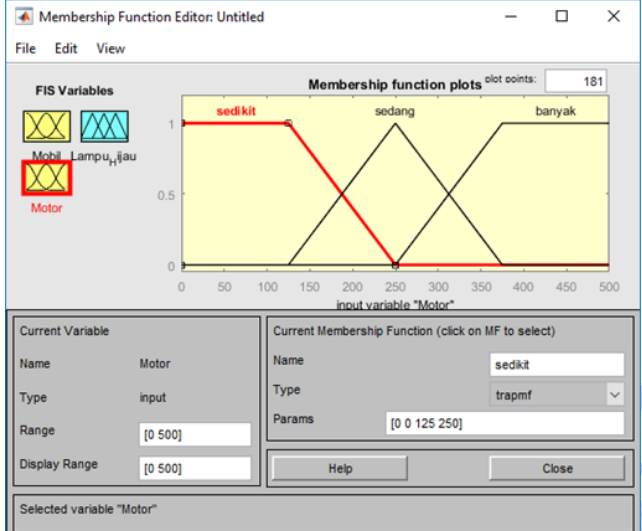

Gambar 3 Input Motor dalam Matlab

Sedangkan range lampu hijau [0 140].Input dalam Matlab adalah sebagai berikut.

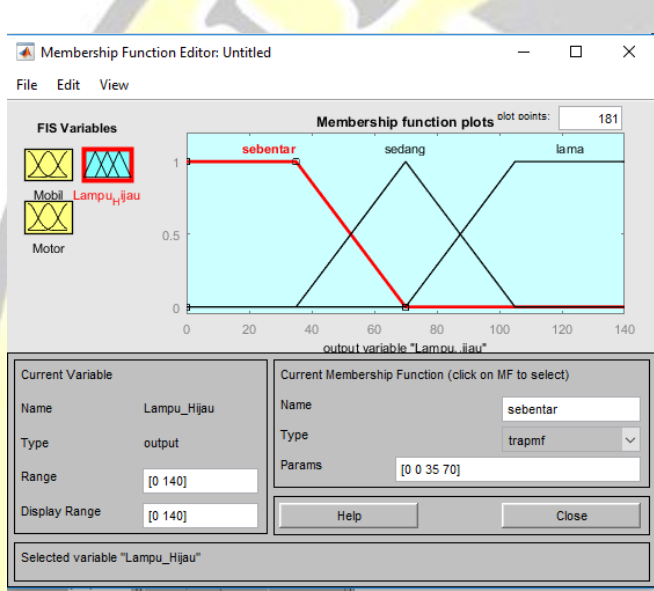

Gambar 4 Input Lama Lampu Hijau dalam Matlab
Rule dalam Matlab ditampilkan sebagai berikut.

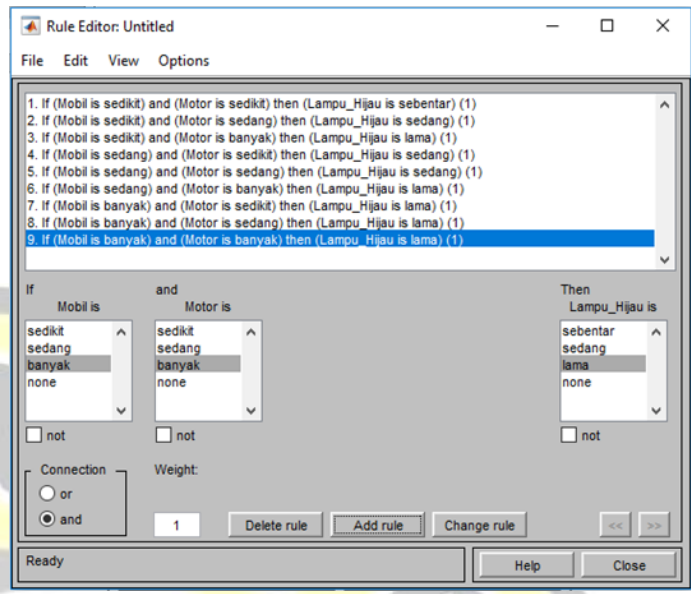

Lama lampu hijau hasil dari Matlab adalah untuk pendekat utara dengan input 26 mobil dan 177 motor akan menghasilkan output lampu hijau 45 detik. Hasil dari Matlab adalah sebagai berikut.

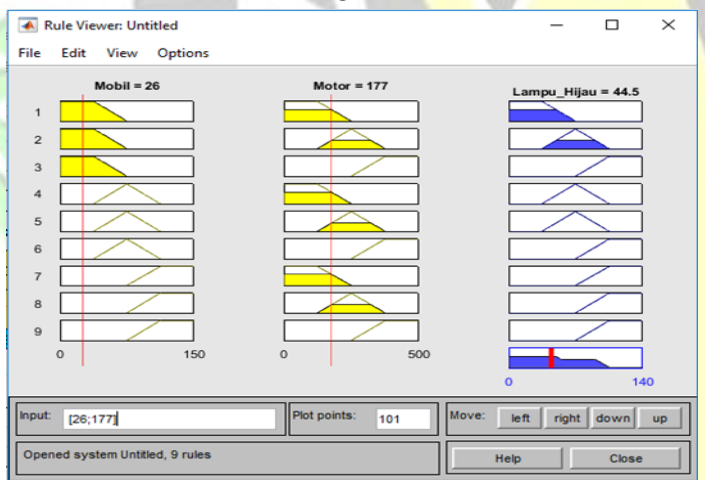

Gambar 6 Hasil Input dan Output Pendekat Utara

Pendekat barat dengan input 25 mobil dan 170 motor akan menghasilkan output 42 detik. Hasil dari Matlab adalah sebagai berikut.

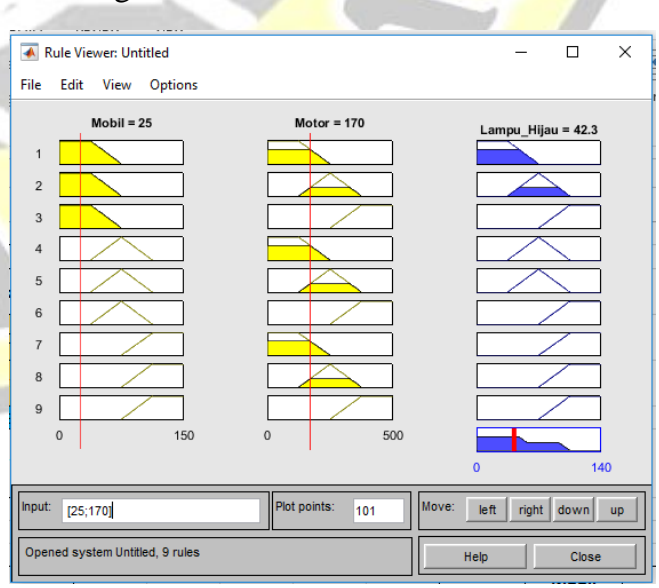

Gambar 7 Hasil Input dan Output Pendekat Barat 


\section{Aplikasi Fuzzy dalam Optimalisasi Traffic Light Persimpangan Juanda}

Sedangkan untuk pendekat timur dengan input 24 mobil dan 168 motor akan menghasilkan lampu hijau 42 detik. Hasil dari Matlab adalah sebagai berikut.

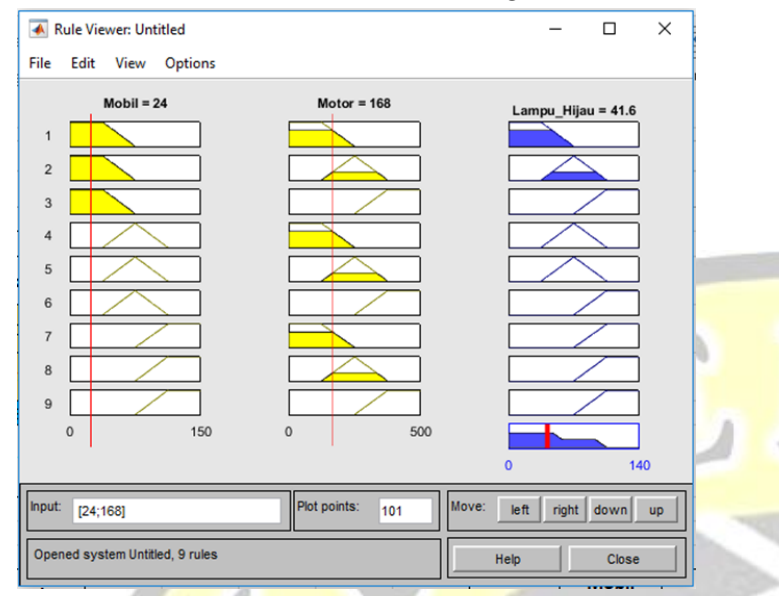

Gambar 8 Hasil Input dan Output Pendekat Timur
Jika ditampilkan dalam bentuk tabel antara input berupa mobil dan motor dengan output lama lampu hijau manual dibandingkan dengan input berupa mobil dan motor dengan output lama lampu hijau yang dihitung dengan menggunakan fuzzy dengan bantuan Matlab maka hasil yang didapat adalah sebagai berikut.

Tabel 6 Hasil Perbandingan Manual dan Fuzzy

\begin{tabular}{clc}
\hline \multirow{2}{*}{ Pendekat } & \multicolumn{2}{c}{$\begin{array}{c}\text { Jumlah mobil dan motor/lama lampu } \\
\text { hijau(siklus) }\end{array}$} \\
\cline { 2 - 3 } & \multicolumn{1}{c}{ Manual } & Fuzzy \\
\hline Utara & $26+177 / 43$ & $26+177 / 45$ \\
\hline Barat & $25+170 / 51$ & $25+170 / 42$ \\
\hline Timur & $24+168 / 53$ & $24+168 / 42$ \\
\hline
\end{tabular}

Dari tabel di atas dapat dilihat perbandingan antara perhitungan output lampu hijau berdasarkan jumlah mobil dan motor dengan manual terlihat kurang optimal dengan memberikan waktu hijau lebih lama untuk jumlah mobil dan motor yang lebih sedikit.Sedangkan dengan fuzzy akan memberikan waktu yang lebih sesuai dengan jumlah mobil dan motor.

\section{PENUTUP}

\section{Simpulan}

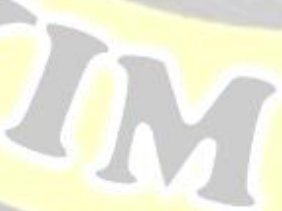

Pada pendekat utara dengan banyak mobil 26 dan motor 177 hasil perhitungan manual mendapatkan lampu hijau 43 detik sedangkan dengan menggunakan fuzzy mendapatkan lampu hijau 45 detik. Pada pendekat barat dengan banyak mobil 25 dan motor 170 hasil perhitungan manual mendapatkan lampu hijau 51 detik sedangkan dengan menggunakan fuzzy mendapatkan lampu hijau 42 detik. Serta pendekat timur dengan banyak mobil 24 dan motor 168 hasil perhitungan manual mendapatkan lampu hijau 53 detik sedangkan dengan menggunakan fuzzy mendapatkan lampu hijau 42 detik. Pendekat utara yang seharusnya mendapat lebih lama lampu hijau, namun berdasarkan perhitungan manual mendapatkan lebih sedikit daripada pendekat barat dan timur. Namun dengan menggunakan fuzzy, pendekat utara dengan jumlah input kendaraan yang lebih banyak daripada pendekat lain mendapatkan lampu hijau yang juga lebih lama dari pendekat barat dan pendekat timur. Hasil dari penelitian menunjukkan bahwa hasil output lama lampu hijau dengan fuzzy lebih menyesuaikan dengan kondisi banyak mobil dan motor yang melewati persimpangan.

\section{Saran}

Bagi peneliti yang akan melakukan penelitian tentang kemacetan lalu lintas mungkin dapat menggunakan metode lain yang dapat dibandingkan dengan fuzzy, sehingga dapat diketahui metode mana yang lebih efektif.

\section{DAFTAR PUSTAKA}

DPU, 1997,."Manual Kapasitas Jalan Indonesia.”, DEPARTEMEN PEKERJAAN UMUM DIREKTORAT JENDERAL BINA MARGA, Jakarta

Kukarni, M.G.H \&Waingakar,"Fuzzy Logic Based Traffic Light Controller.Proc. 2009 IEEE Student Conf Res.2007;501-509

Kusumadewi,Sri,dkk. 2010. Aplikasi Logika Fuzzy untuk Pendukung Keputusan. Yogyakarta:Graha ilmu.

Prasetiyo, Erwan Eko. 2016."Perbandingan Kinerja Pengendalian Lampu Lalu Lintas Metode Fuzzy Tipe Sugeno dengan Metode Waktu Tetap",Seminar Nasional Teknologi Informasi dan Multimedia 2016. ISSN:2302-3805

Undang-undang Nomor 22 Tahun 2009, Lalu Lintas dan Angkutan Jalan.

Zhang, L. Wu\& Shi, Z. 2010.”An Intelligent Fuzzy Control for Crossroad Traffic Light", 2010 Second WRI Glob. Congr. Intell Sysyt.pp2832. Dec. 2010 